\title{
MOUNTAINS OF THE MOON
}

\author{
Amerikaanse film van Bob Rafelson met Patrick Bergin en Ian Glenn, 1989
}

\section{De geschiedenis van de ontdekking van de bronnen van de Nijl.}

De oudste kaart van Centraal- en Oost-Afrika is deze van Ptolemaeus (2de eeuw A.D.), waarop grote meren en de 'Bergen van de Maan' (vermoedelijk de Ruwenzori) gesitueerd zijn. De pharao meende, niet ten onrechte, dat men de bronnen van de Nijl in die regio moest zoeken. Veel later hebben ook Portugezen en Arabische ivoor- en slavenhandelaars hierover bericht. Pas in de eerste helft van de 20 ste eeuw kon duidelijk bewezen worden dat de zuidelijkste bron van de Nijl in Burundi ontspringt.

In de tweede helft van de 19de eeuw veroorzaakte de zoektocht naar de bronnen van de Nijl grote opwinding in gans Europa, waar er brede belangstelling voor de politieke én economische gevolgen van de ontdekking bestond.

In 1857 worden de Britse luitenant John Hanning Speke en de Ierse kapitein Richard Burton door de Royal Geographical Society uitgezonden. Zij vertrekken vanuit Zanzibar om, via Bagamoyo en Tabora, het Tanganyikameer in Ujiji te bereiken. Nadien verkennen ze het noorden van het meer en de Rusizirivier. Terug in Tabora aangekomen, trekt Speke alleen naar het noorden en bereikt hij de zuidpunt van het Victoria-Nyanzameer. Hij meent de bronnen van de Nijl ontdekt te hebben.

Tijdens een tweede tocht, van 1862 tot 1864 , nu samen met James Grant, bereikt Speke in juli 1862 de Ripponwatervallen, waar de Nijl uit het Victoriameer stroomt. In die streek ontmoeten ze Samuel Baker. Op zoek naar Speke, vaarde Baker de Nijl op en ontdekte hij zo het Mobutumeer (ex-Albertmeer), als deel van het Nijlsysteem. Burton wordt jaloers op Speke en poogt, vernuft maar onjuist, aan te tonen dat het Tanganyikameer de bron van de Nijl is.

De dag waarop de confrontatie tussen beide mannen op de Royal Geographic Society in Londen zou plaats hebben, daagde Speke niet op. Hij verongelukte kort voordien als gevolg van een jachtongeval (zelfmoord?).

De geografische twijfels bleven bestaan en moedigden David Livingstone aan om de bronnen van de Nijl verder zuidwaarts te zoeken. Op 10 november 1871 ontmoette 


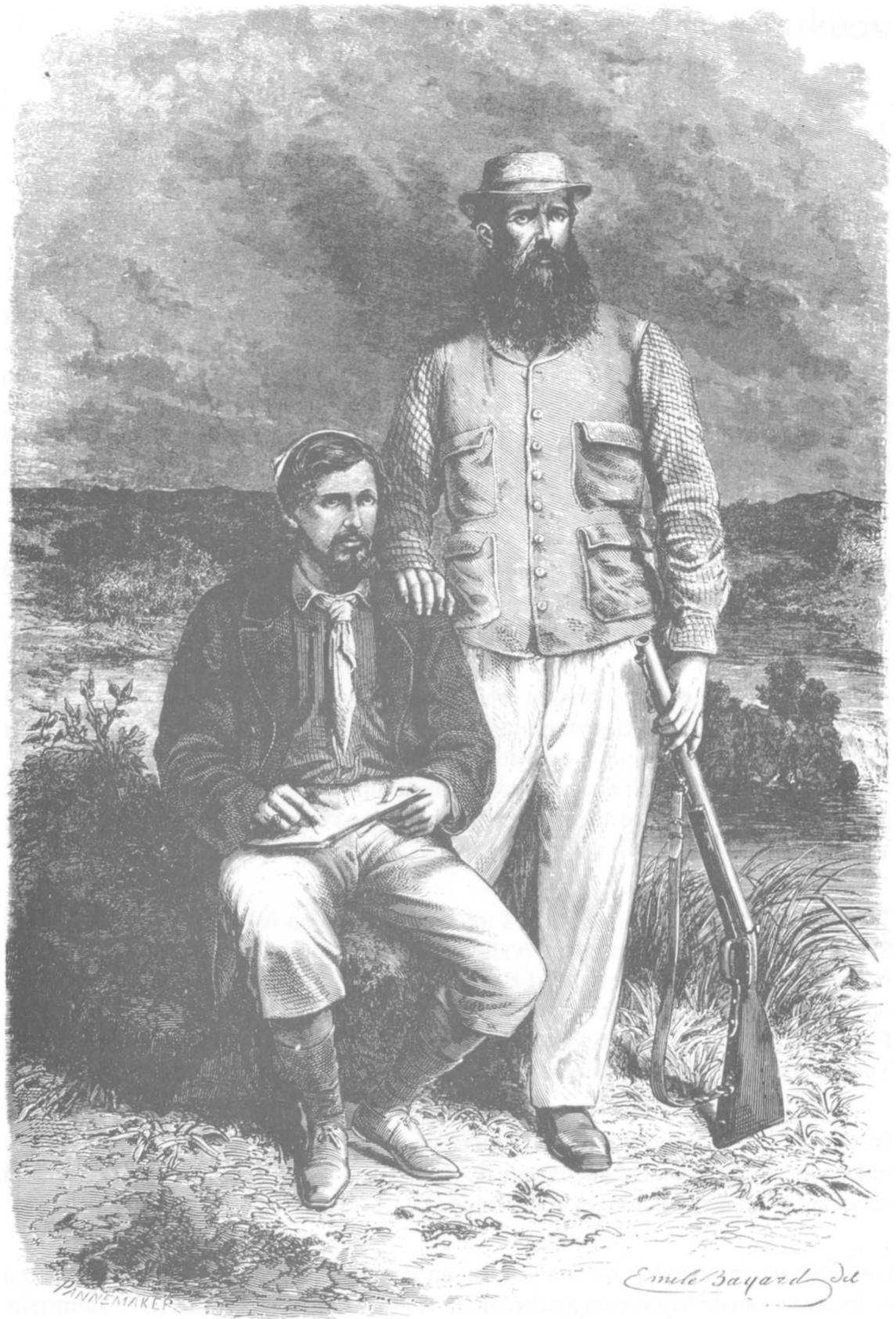

Le capitaine Grant et le capitaine Speke 
Henry Morton Stanley de zieke Dr. Livingstone te Ujiji. Samen hebben ze in 1872 de noordelijke kust van het Tanganyikameer opnieuw geëxploreerd. In Burundi wil men de mensen doen geloven dat die ontmoeting plaats vond op een twintigtal kilometer ten zuiden van Bujumbura, waar een monoliet opgesteld staat als aandenken van deze historische gebeurtenis.

Het was tenslotte Stanley die in 1875-1876 Speke gelijk gaf en een einde maakte aan het enigma van de bronnen van de Nijl.

Verder onderzoek toonde aan dat de zuidelijkste bron van de Nijl in de nabijheid van Rutovu, in Burundi, op de Kigizi heuvel ontspringt. In 1937 heeft Dr. Burkhart Waldecker de Kasumo ontdekt op een hoogte van $2.050 \mathrm{~m}$. Hij heeft er een pyramide laten bouwen en de bron laten inmetselen. Op de pyramide werd later een koperen plaat aangebracht ter nagedachtenis van de vele ontdekkingsreizigers en de verschillende namen die de Witte Nijl achtereenvolgens draagt vooraleer hij in Kartoem samenvloeit met de Blauwe Nijl.

In 1974 heb ik, samen met een multidisciplinair wetenschappelijk team, tijdens een veertiendaagse tocht vanuit Rutovu, de Ruvyironza afgevaren tot Mugera. Deze expeditie heeft ertoe bijgedragen deze verraderlijke rivier, met zijn talrijke watervallen, beter in kaart te brengen. Deze filmbespreking is dan ook een hommage aan de onlangs overleden Burundese radioreporter, Robert Nsengi, die deel uitmaakte van het team.

\section{De geschiedenis volgens Rafelson en Harrison.}

Bob Rafelson baseerde zijn film op de geromantiseerde biografie 'Burton and Speke' van William Harrison.

In dit verhaal worden, nadat ze het Tanganyikameer "ontdekt" hebben en naar Tabora terugkeren, Burton en Speke gevangen genomen door het leger van een zekere 'Lord Ngola' (koning Mutesa dus). Speke krijgt evenwel de toelating om met enkele van zijn dragers naar het noorden te trekken. Burton blijft als gegijzelde aan het hof. Zoals we weten gebeurde die episode pas in 1862 samen met Grant als Spekes reisgezel.

Het einde van de film verhaalt de onenigheid tussen Burton en Speke nadat ze het Tanganyikameer ontdekt hebben en nadat Speke alleen het zuiden van het Vic- 


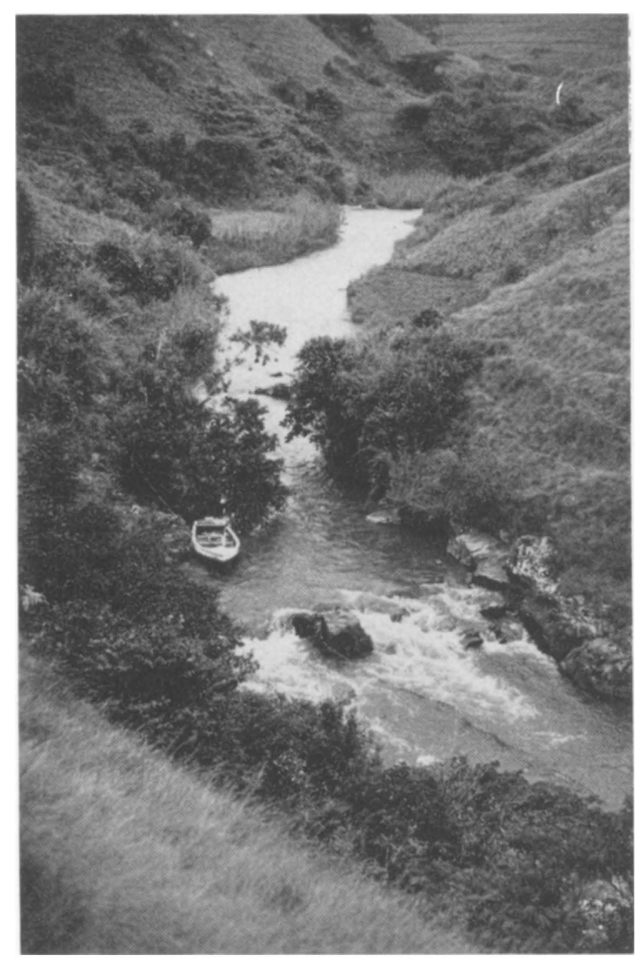

De Ruvyironza in Burundi vormt de meest zuidelijke rivier van de $\mathrm{Nijl}$

(C) P. Wymeersch

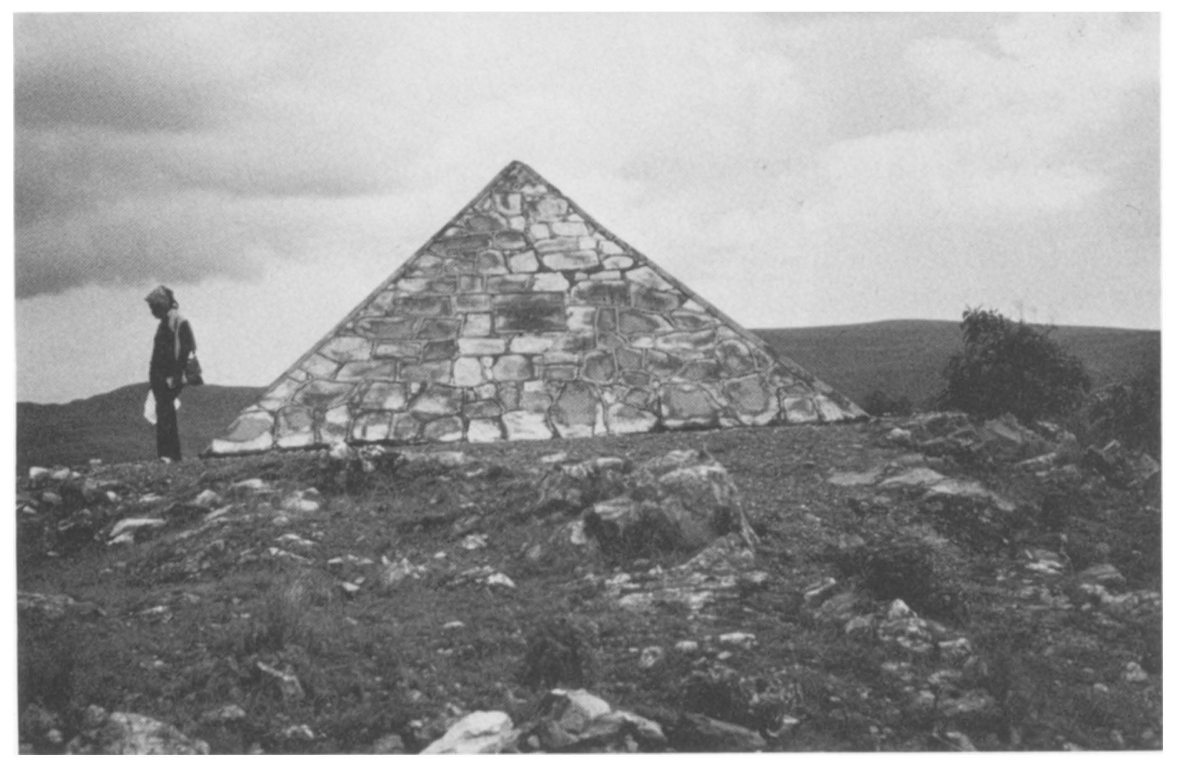

Kasumo, de echte bron van de Nijl, met daarop de in 1937 opgerichte pyramide. Dit uiteindelijk doel van vele ontdekkingsreizigers ligt nabij Rutovu in Burundi.

(C) P. Wymeersch 
toriameer heeft bereikt. In werkelijkheid is de twist tussen beiden pas ontstaan na de terugkomst van Spekes tweede expeditie in 1864.

\section{Kritiek}

Positief in het filmverhaal is dat Rafelson geïnteresseerd was in de relatie van Burton en Speke tegenover hun gidsen en dragers. Vaak werden deze Afrikaanse mensen niet eens vernoemd in de dagboeken van de ontdekkingsreizigers. De reisroutes die door Burton en andere explorators werden gevolgd, waren reeds veel vroeger opengesteld of uitgebreid door Afrikanen zelf en door Arabische of gearabiseerde slaven- en ivoorhandelaars. Europeanen vergeten maar al te vaak dat de "ontdekkingen" gelukt zijn mede en dankzij de inlandse gidsen en dragers die de regio's kenden en de stamtalen spraken. Rafelson heeft die mensen uit de anonimiteit gehaald en postuum in ere hersteld.

Positief is ook de reconstructie van het paleis van koning Mutesa en de entourage van het koninklijk hof. Mutesa, een goddelijke vorst die de titel Kabaka droeg, leefde in de hoofdstad Mmengo (het latere Kampala) van het Bugandarijk. De film toont ons o.a. het gebruik dat de vorst op een gehurkte onderdaan kan zitten en dat hij omringd wordt door de sacrale trommen die zijn macht en gezag symboliseren.

In een recent interview met P. Duynslaegher in Knack (Nr. 16, 1990) wordt het etnografisch onderzoek van Rafelson bewierookt. Al is zijn prent stukken beter dan de gebruikelijke Hollywoodcinema over Afrika, zoals 'King Salomon's Mines' en hij gefeliciteerd werd door Amerikaanse antropologen voor de etnografische reconstructie bij een aantal etnische groepen, ben ik van oordeel dat die lof getemperd moet worden en wel om volgende redenen :

1. In de omgeving van Tabora, ontmoeten Burton en Speke Arabische slavenhandelaars die blijkbaar temidden van de ... Turkana (noordwest Kenya) leven! In werkelijkheid hebben beide ontdekkingsreizigers nooit dit gebied doorkruist. De eerste blanken die het Turkanameer (ex-Rudolfmeer) in 1888 bereikten waren de Hongaarse graaf Samuel Teleki von Szek en de Oostenrijkse luitenant Ludwig von Höhnel. Er is dus geen sprake van een "reconstructie van de etnografie", want de Turkana delen vandaag de dag nog altijd dezelfde levenswijze als op de prent en lopen er nog altijd zo opgesmukt bij. Dezelfde kritieken gelden voor de ten tonele gebrachte Maasai die op de grens tussen Kenya en Tanzania leven en de Rendille van noordoost Kenya met wie Burton en Speke geen contacten kunnen gehad hebben. 


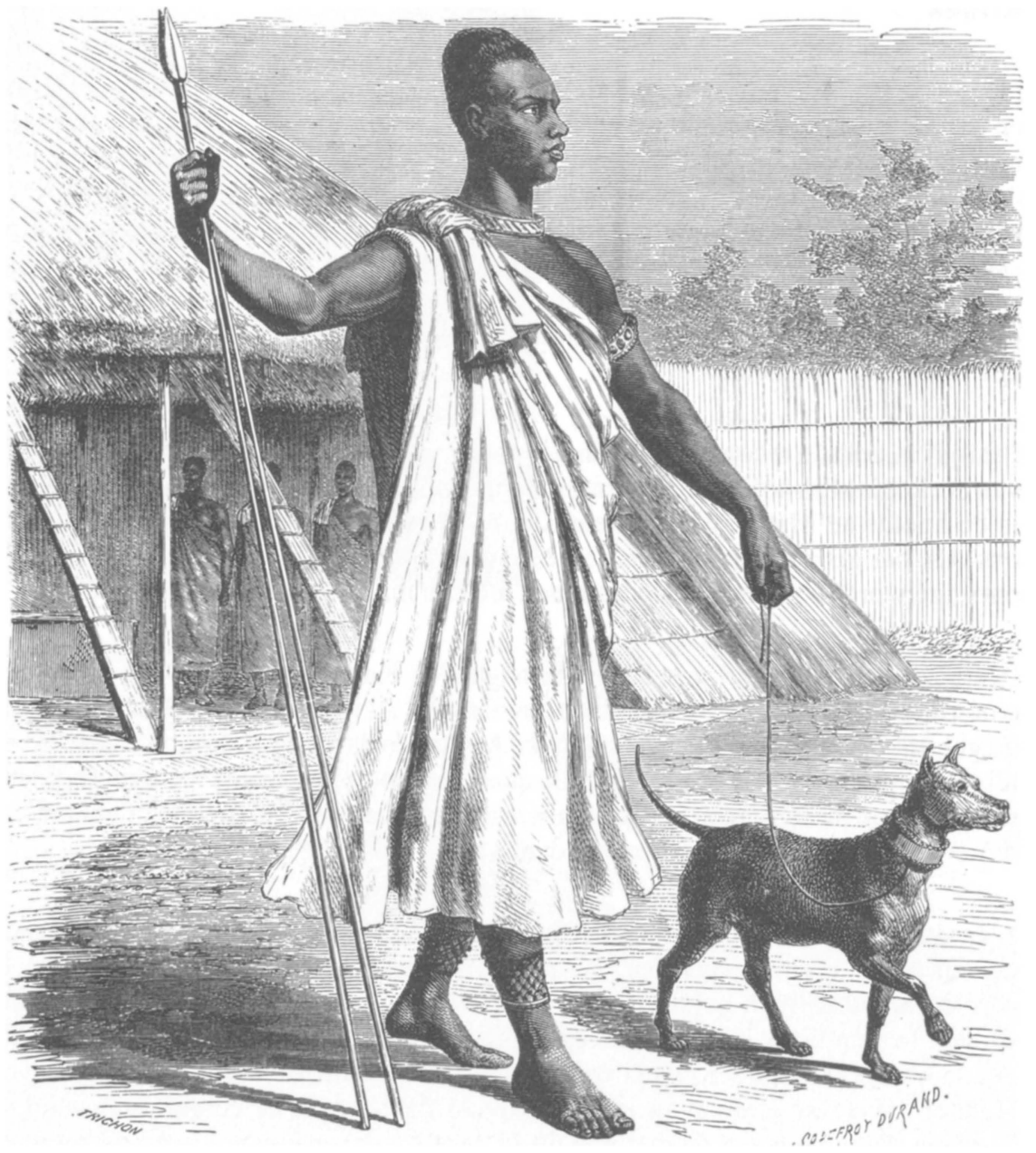

S.M. Mtésa, roi de l'Ouganda 
2. Ten tweede legt Rafelson teveel de nadruk op de wreedheid (slavenhan$\mathrm{del} /$ koninklijk hof van Mutesa) en de onhandigheid (het laten vallen van een dekseltje in het theekopje) van de Afrikanen. Dergelijke clichés en stereotiepen over Afrikanen kunnen de westerse mentaliteit ter zake alleen maar consistenter maken, of m.a.w. : Afrikanen zijn bloeddorstig én onhandig.

3. Tenslotte stelt Rafelson een niet-racistische Burton voor. In werkelijkheid was hij lang niet vrij van racisme niettegenstaande hij een bekend Arabist was, meer dan twintig talen sprak en etnologische studies verrichtte. Hij schreef o.m. het volgende: "De studie van de neger is de studie van mensen zonder geestelijke ontwikkeling [...] Het lijkt mij toe dat hij (de neger) behoort tot een van die kinderlijke rassen [...] ". De meeste ontdekkingsreizigers, en Burton maakt hierop geen uitzondering, brachten weinig juiste of genuanceerde inlichtingen mee over de volken met wie ze contact hadden. $\mathrm{Zij}$ waren slachtoffers geworden van hun eigen racistische theorieën.

Een best genietbare film.

Bespreking door :

Patrick WYMEERSCH

College voor de Ontwikkelingslanden (RUCA)

Middelheimlaan 1

2020 Antwerpen 


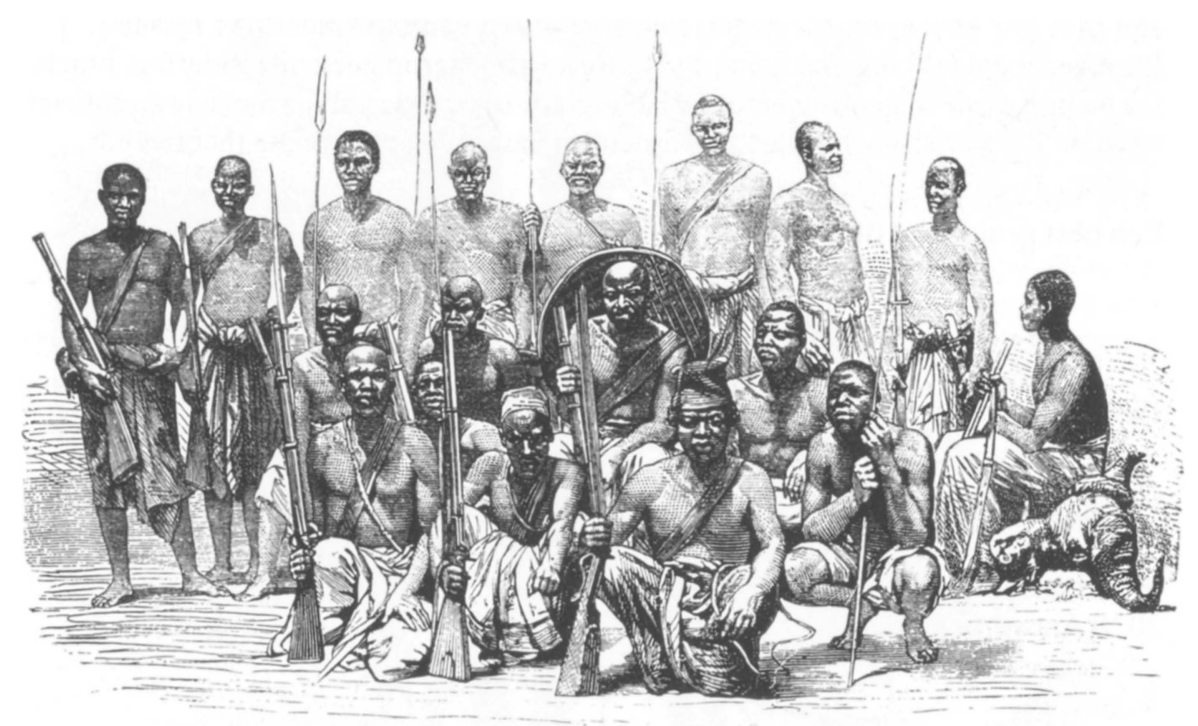

Les "fideles" des capitaines Speke et Grant - D'apres une photographie Gravures uit: Capitaine Speke. Les sources du Nil. Journal d'un voyage de découvertes. In: Le Tour du Monde. Nouveau Journal des Voyages, 1864 premier semestre, Paris, Hachette, p. 273, 337 en 348. 